\title{
PARCERIA NA FORM(AÇÃO) DOCENTE: O ESTÁGIO CURRICULAR SUPERVISIONADO COMO LUGAR DE FRONTEIRA DOS CURSOS DE FORMAÇÃO E A EDUCAÇÃO BÁSICA
}

\author{
ASOCIACIÓN EN LA FORMACIÓN DOCENTE: LA ETAPA CURRICULAR \\ SUPERVISADO COMO LUGAR DE FRONTERA DE LOS CURSOS DE FORMACIÓN \\ Y LA EDUCACIÓN BÁSICA
}

\author{
PARTNERSHIP IN TEACHER TRAINING: THE SUPERVISED CURRICULAR \\ INTERNSHIP AS A FRONTIER PLACE FOR TRAINING COURSES AND BASIC \\ EDUCATION
}

RESUMO: Objetiva-se socializar reflexões acerca de gargalos da form(ação) docente, causados pela ausência de uma relação de parceria institucionalizada entre as Instituições de Ensino Superior e as escolas de Educação Básica. Trata-se de uma pesquisa cuja abordagem metodológica deriva de um híbrido constituído por procedimentos da História Oral e da Análise de Conteúdo. Toma o Estágio Curricular Supervisionado (ECS) como promissor para a relação institucionalizada de parceria na formação docente. Conclui-se por sugerir o aprofundamento de reflexões que possibilitem a institucionalização dos sistemas estaduais e municipais de ensino como co-responsáveis pela formação docente, atribuindo carga horária para o professor que receber e acompanhar licenciandos para realização do ECS.

PALAVRAS-CHAVE: Estágio curricular supervisionado. Formação docente. Parceria.

RESUMEN:El objetivo es socializar reflexiones sobre los cuellos de botella de la forma de enseñanza (acción), causados por la ausencia de una relación de asociación institucionalizada entre las instituciones de educación superior y las escuelas primarias. Esta es una investigación cuyo enfoque metodológico deriva de un híbrido que consiste en procedimientos de Historia Oral y Análisis de Contenido. Toma la pasantía curricular supervisada (ECS) como prometedora para la relación institucionalizada de asociación en la formación docente. Concluye sugiriendo la profundización de las reflexiones que permiten la institucionalización de los sistemas educativos estatales y municipales como corresponsables de la educación docente, asignando la carga de trabajo al maestro que recibe y acompaña a los graduados para realizar el ECS.

PALABRAS CLAVE: Etapa curricular supervisada. Formación docente. Asociación.

ABSTRACT: The objective is to socialize reflections about the bottlenecks of the teaching form (action), caused by the absence of an institutionalized partnership relationship between

${ }^{1}$ Instituição: Universidade Federal do Espírito Santo (UFES), Vitória - ES - Brasil. Professor Adjunto do Centro de Educação e Professor Permanente do Programa de Mestrado Profissional em Educação, Departamento de Educação, Política e Sociedade. ORCID: http://orcid.org/0000-0002-0846-0621. E-mail: vilmar.geo@gmail.com 
the Higher Education Institutions and the Elementary Schools. This is a research whose methodological approach derives from a hybrid consisting of procedures of Oral History and Content Analysis. It takes the Supervised Curricular Internship (ECS) as promising for the institutionalized relationship of partnership in teacher education. It concludes by suggesting the deepening of reflections that enable the institutionalization of state and municipal education systems as co-responsible for teacher education, assigning workload to the teacher who receives and accompany graduates to perform the ECS.

KEYWORDS: Supervised internship. Teacher training. Partnership.

\section{Palavras iniciais}

O presente texto tem por objetivo socializar reflexões acerca de gargalos na form(ação) docente, causados pela ausência de uma relação de parceria entre as Instituições de Ensino Superior e as escolas de Educação Básica. Para tanto, toma o Estágio Curricular Supervisionado como "zona de fronteira", e, portanto, como disciplina promissora para a efetivação de uma relação institucionalizada de parceria na formação docente.

De acordo com Valladares (2009), zonas de fronteiras são habitats de encontros com aquilo que não se é, mas que já pressiona sua (nossa) existência. Nessa direção, depreende-se que o Estágio Curricular Supervisionado pode ser tomado como zona fronteiriça entre a condição de estudante em processo de formação inicial e sua atuação como estagiário, assumindo a docência em escolas de educação básica.

Diante de tal premissa, buscamos por narrativas de professores responsáveis pela disciplina Estágio Curricular Supervisionado nos cursos de licenciatura em Geografia, História, Filosofia e Ciências Sociais da Universidade Federal do Espírito Santo que desvelassem os caminhos percorridos no estabelecimento de elos entre a Universidade e as Escolas de Educação Básica. Essa busca se apoiou nos procedimentos metodológicos da História Oral (BOM MEIHY, 1996) como alternativa para coleta de dados empíricos.

A ordenação dos depoimentos, nem sempre narrados de forma linear, se pautou na técnica Análise de Conteúdos formulada por Bardin (1988), que a concebe como

Um conjunto de técnicas de análise das comunicações visando obter, por procedimentos sistemáticos e objetivos de descrição do conteúdo das mensagens, indicadores (quantitativos ou não) que permitam a inferência de conhecimentos relativos às condições de produção/recepção (variáveis inferidas) destas abordagens (BARDIN, 1988, p. 42). 
A opção pela análise das fontes orais utilizando-se dos pressupostos da Análise de Conteúdos proposta por Bardin (1988) se pauta, também, pelas recomendações de Delgado (2006, p. 29-30), ao afirmar que:

As seguintes etapas podem, em muito, contribuir para a interpretação das entrevistas: análise temática de seus conteúdos, destacando-se temas gerais; [...] realizar agrupamento de um conjunto de entrevistas no qual cada depoimento possa se constituir como unidade especial, e o conjunto deles possa ser cruzado, comparando-se as versões e as informações obtidas.

Nesse sentido, após a exploração do material, caracterizado pelo momento em que os dados brutos das entrevistas são codificados, foi identificada como categoria de análise a unânime denúncia dos entrevistados com relação à necessidade do estabelecimento de uma relação de parceria entre a Universidade e as Escolas de Educação Básica, que possibilitasse o desenvolvimento do Estágio Curricular Supervisionado.

A análise da legislação educacional e também da bibliografia específica sobre a matéria nos revelam que, historicamente, o Estágio Curricular Supervisionado e a Prática de Ensino sempre fizeram parte das preocupações e das discussões sobre a formação docente. No entanto, a ausência de uma relação interinstitucional de parceria tem contribuído para a manutenção da equivocada dicotomia entre a dimensão teórica e a dimensão prática na formação docente, instituindo, também, uma certa hierarquização de saberes, com a sobreposição dos saberes acadêmicos sobre os saberes da prática.

Pimenta e Lima (2010) asseveram que um caminho possível para a superação dessa histórica relação dicotômica seria a consideração do Estágio Curricular Supervisionado como campo de conhecimento, visando, além da inserção do formando no campo de trabalho, no intuito de experimentar e exercitar a profissão, tomar tal inserção como momento formativo, propiciando que as discussões e reflexões decorrentes das observações e vivências realizadas no campo de Estágio integrem realmente o processo de formação do futuro professor. Isso significa conceber o campo de atuação no qual está inserido como objeto de análise, de investigação, ou seja, “campo de conhecimento" (PIMENTA; LIMA, 2010, p. 24).

A pertinência de se encarar o Estágio Curricular Supervisionado como campo de conhecimento, conforme defendem as autoras acima, visa a superação da tradicional redução a ele atribuída de ser meramente uma atividade prática instrumental. No entanto, inúmeros tem sido os obstáculos a serem superados para tal efetivação. O que se percebe, tanto nas narrativas de pesquisas que tomam o Estágio Curricular Supervisionado como objeto de estudos, como também pautados em nossas práticas e vivências, enquanto professor 
responsável por tal disciplina na Licenciatura em Geografia, é que um caminho viável e necessário para tal efetivação passa, obrigatoriamente, por uma aproximação dos cursos de formação com as escolas de educação básica.

Conceber o Estágio Curricular Supervisionado como campo de conhecimento pode ser um bom passo para se alcançar a interação acadêmica tão desejável entre os cursos de Licenciatura e as escolas-campo. Para tanto se faz necessário considerar que todos os sujeitos envolvidos são agentes formadores, ou seja, tanto os professores supervisores, responsáveis pela condução da disciplina nos seus respectivos cursos de formação, como também os professores parceiros, que recebem alunos estagiários no cotidiano de suas salas de aulas.

Ambos são formadores igualmente. Portanto, no processo de formação docente, o Estágio Curricular Supervisionado pode ser encarado como zona de fronteira entre a academia e a escola de educação básica. Para a objetivação e desenvolvimento da ementa e as respectivas propostas de atividades previstas na legislação que a regulamenta, o Estágio Curricular Supervisionado se coloca em um espaço-tempo de "não-lugar", onde o licenciando não é totalmente estudante e nem também é necessariamente docente. É um sujeito em construção, que buscando formar-se profissional exerce, ainda que momentaneamente, a profissão, colocando-se numa zona de fronteira entre o ser/estar estudante e o ser/estar professor.

Igualmente o Estágio Curricular Supervisionado, enquanto disciplina obrigatória da grade curricular dos cursos de formação docente, mantidos pelas Instituições de Ensino Superior, também se coloca num espaço-tempo de não-lugar. Para efetivar-se em sua dialética dimensão teórico-prática necessita estar/realizar-se tanto na Instituição de Ensino Superior, quanto em unidades escolares da Educação Básica. Portanto, também ocupa uma zona de fronteira, onde a linha que separa as duas instituições de ensino, a Superior e a da Educação Básica, se mostra bastante tênue.

Coloca-se, enfim, em uma zona fronteiriça.

A zona fronteiriça é uma zona híbrida, babélica, onde os contatos se pulverizam e se ordenam segundo micro-hierarquias pouco suscetíveis de globalização. Em tal zona, são imensas as possibilidades de identificação e de criação cultural, todas igualmente superficiais e igualmente subvertíveis... (SANTOS, 1993, p. 49).

Nessa direção, também se torna de mister importância considerar que uma análise acerca de estudos e reflexões abordando as contribuições do Estágio Curricular Supervisionado para a formação docente nos revela certo consenso entre os pesquisadores, 
que para a sua efetivação faz-se necessária uma aproximação dos Cursos de formação docente com as escolas de educação básica.

Essa percepção se torna ainda mais evidente se nos apoiarmos na definição de Estágio Curricular Supervisionado, explícita no Parecer CNE/CP 28/2001, que ao estabelecer a duração e a carga horária dos cursos de formação de professores, atribui ao Estágio Curricular Supervisionado uma carga horária mínima de 400 horas, a ser oferecida a partir da segunda metade do curso.

Segundo tal Parecer,

[...] estágio curricular supervisionado de ensino entendido como o tempo de aprendizagem que, através de um período de permanência, alguém se demora em algum lugar ou ofício para aprender a prática do mesmo e depois poder exercer uma profissão ou ofício. Assim, o estágio curricular supervisionado supõe uma relação pedagógica entre alguém que já é um profissional reconhecido em um ambiente institucional de trabalho e um aluno estagiário. Por isso é que este momento e chama estágio curricular supervisionado (BRASIL, p. 9).

Evidencia-se, assim, que os cursos de formação inicial de professores necessitam buscar uma relação de aproximação com as escolas de educação básica, na perseguição dos objetivos e propósitos formativos da disciplina.

No entanto, embora prevista na legislação, essa aproximação vem se efetivando, via de regra, somente por intermédio de relações interpessoais. Trata-se de relações estabelecidas entre professores dos cursos de formação inicial, responsáveis pela disciplina Estágio Curricular, e professores atuantes na Educação Básica, que se dispõem receber licenciandosestagiários em suas salas de aulas.

É nesse movimento que, historicamente, se tem conseguido possibilitar aos licenciandos "um período de permanência" no interior da escola de educação básica, para o estabelecimento de uma "relação pedagógica entre alguém que já é um profissional reconhecido em um ambiente institucional de trabalho", que lhe possibilite "aprender a prática do mesmo e, depois exercer uma profissão ou ofício".

\section{Parceria colaborativa: aproximando a Instituição Superior e a Educação Básica}

Uma análise na história da formação docente no Brasil desvela que a relação entre os cursos de formação inicial e as escolas de educação básica tem sido marcada pela ausência de uma institucionalização de tal processo. Essa ausência tem sido um verdadeiro obstáculo para 
a formação docente, se caracterizando como um grande fosso que distancia instituições formadoras e instituições da educação básica.

Destaca-se, assim, a necessidade de estudos e reflexões que contribuam e viabilizem caminhos para a institucionalização da aproximação entre as instituições que formam os profissionais docentes.

Nessa direção, é latente a necessidade de se romper com a histórica e equivocada concepção de que somente as Instituições de Ensino Superiores formam os professores. Ora, conforme já mencionado anteriormente, o Estágio Curricular Supervisionado é uma disciplina que se coloca em uma zona de fronteira. Embora componha a grade curricular obrigatória dos cursos de licenciatura, portanto, de responsabilidade da Instituição de Ensino Superior, por sua essência, para efetivar-se conforme estipulado na legislação que o normatiza, necessita ser desenvolvido em instituições da Educação Básica. Portanto, as escolas que se propõem em receber alunos estagiários também são instituições formadoras de tais futuros profissionais.

Decorre daí a necessidade de estabelecimento de uma relação de parceria entre tais instituições, visto que, conforme já discutido anteriormente, um dos caminhos viáveis e possíveis para a necessária e urgente institucionalização da aproximação entre a Instituição de Ensino Superior e as instituições de ensino da educação básica passa pela busca de uma parceria no processo de form(ação) docente.

De acordo com Foerste (2005), a questão do estabelecimento de um sistema colaborativo de parceria na formação e desenvolvimento de professores, compreendendo a busca de construção coletiva de um projeto educacional emancipatório, é um objeto de pesquisa bastante recente no Brasil, embora desde a primeira metade dos anos 1990 tenha recebido destaque no contexto internacional, tais como no Reino Unido, na França, no Canadá, e em Portugal.

Entende-se, aqui, a parceria colaborativa como esforços de construção coletiva de um projeto de formação e desenvolvimento profissional que envolva formação do professor na universidade e suas interfaces com as instituições de ensino básico, com vistas a abolir a visão dualista e hierárquica, equivocadamente estabelecida entre saberes e práticas. Trata-se de um projeto de Educação que envolva e se constitui pelo/no

[...] estabelecimento de relações entre diferentes sujeitos e instituições (governo, universidades, escolas, sindicatos, profissionais do ensino em geral, etc, que passam a estabelecer interações para tratar de interesses comuns, construindo e implementando programas a partir de objetivos partilhados, com a definição de atribuições ou competências institucionais (FOERSTE, 2005, p. 37-38). 
Reafirmando a necessidade do estabelecimento de uma relação de parceria, conforme defende Foerste (2005), encontramos as contribuições de Tardif (2008), que ao analisar programas de ensino considerados como de qualidade, destaca como característica comum na pesquisa internacional sobre a formação para o ensino a existência de fortes parcerias com o meio escolar.

Conforme Tardif (2008), a essência do resultado positivo de um sistema de parceria é o ciclo que ele estabelece, pois ao garantir a melhoria da qualidade da formação docente, automaticamente se garante, em médio e longo prazos, a melhoria da qualidade do ensino básico, visto que futuramente serão os professores formandos (estagiários) que estarão atuando como profissionais daquele nível e rede de ensino.

Como bem salienta Tardif (2008, p. 24), a formação dos docentes deve ser concebida e implementada no sistema de parceria, como uma "co-formação entre os formadores do Ensino Superior e os docentes de estabelecimento que acolhem os estagiários", que também são formadores, visto que é no exercício de sua função que o docente mobiliza os diferentes saberes que o constitui como profissional. Portanto, é na prática da função que se efetiva a construção da identidade docente e, como tal, é nesse movimento que ocorre na prática que se devem fundamentar os projetos de formação inicial e contínua do docente.

Nesse sentido, justificam-se esforços e reflexões com vistas à formalização e reconhecimento das relações de parcerias estabelecidas nesse momento formativo. A parceria na formação docente exige a negociação e partilha de compromissos institucionais, pois a mesma se efetiva na articulação do trabalho colaborativo entre profissionais do ensino (professores universitários e professores do ensino básico), bem como entre universidade e secretarias de ensino e suas unidades escolares de Educação Básica.

Para estabelecimento de uma relação de parceria institucionalizada, com vistas à busca por melhoria na qualidade da formação docente, o Estágio Curricular Supervisionado apresenta-se como elo essencial a essa corrente. O Estágio, em todas as suas fases e concepções, envolve diferentes sujeitos, sejam os alunos estagiários, sejam professores supervisores ou parceiros. Envolve, também, diferentes instituições, tais como os respectivos cursos de formação universitária e as unidades escolares em que ocorrem as atividades práticas do ensino. Portanto, só pode acontecer, como de fato vem acontecendo ao longo de sua história, por meio de relações de parcerias. No entanto,

[...] esse trabalho integrado resultava de iniciativas e esforços individuais, geralmente centradas na boa vontade e compromisso de professores de 
algumas disciplinas do currículo dos cursos de licenciatura e algumas escolas. Raramente a relação estabelecida obedecia a acordos interinstitucionais, com regras negociadas, construídas a partir de reflexões coletivas sobre a prática docente (nas escolas e na universidade). Nessa parceria predominavam pressupostos teórico-práticos que acabavam sobrepondo o saber acadêmico aos saberes práticos dos profissionais do ensino básico. (FOERSTE, 2004, p. 3).

Essas relações de parceria, de uma maneira ou de outra, vem ocorrendo. No entanto, lamentavelmente, se não formalizadas e nem institucionalizadas ficam, na maioria das vezes, no âmbito das relações interpessoais e sem a devida valorização, validação e reconhecimento.

A não institucionalização de tais parcerias acarreta, também, conforme denunciado por Foerste (2004), uma hierarquização dos saberes acadêmicos em detrimento de saberes da experiência, mobilizados, produzidos e reproduzidos pelos professores da educação básica em seu cotidiano de sala de aula.

Conforme bem salientam Tardif (2000) e Gauthier (1998), o exercício da função docente exige a mobilização de uma pluralidade de saberes. Tais saberes não podem ser hierarquizados, considerados isoladamente como capazes de subsidiar a prática da profissão. Também não podem ser tomados de forma estanque ou linear, visto que um não vem, necessariamente, em decorrência de outro, em uma ordem pré-estabelecida, mas que, dialeticamente, um influencia e é influenciado pelos demais.

Assim, a institucionalização de uma relação de parceria que reconheça o professor atuante na educação básica, que recebe, acompanha e orienta estagiários, contribui para o reconhecimento de tal profissional como sujeito formador e, ainda, rompe com o equívoco de hierarquizar e sobrepor o saber acadêmico, epistêmico, sobre o saber da experiência.

O relevante e necessário estabelecimento de uma relação institucionalizada de parceria na formação docente para efetivar e potencializar as contribuições formativas do Estágio Curricular Supervisionado fica bastante evidenciado em narrativas disponíveis em pesquisas com foco no Estágio Curricular Supervisionado na formação docente.

Por exemplo, em pesquisa abordando a multiculturalidade e os processos de identificação na formação docente, Corradi (2005) nos mostra a importância e mesmo a necessidade do estabelecimento de um processo de colaboração e parceria no desenvolvimento do Estágio Curricular Supervisionado.

Vale dizer que a pesquisadora, por ocasião do desenvolvimento de sua pesquisa, atuava profissionalmente como uma parceira, recebendo em suas aulas de Química do Curso Médio, alunos estagiários do curso de Licenciatura em Química. Segundo sua narrativa, a 
relação de parceria trouxe benefícios para ambas as partes. Tanto para os estagiários quanto para a professora experiente, que era.

Em suas palavras,

[...] fica claro para mim o quanto foi importante essa parceria. Se ao recepcionar esses estagiários estava contribuindo para a formação inicial deles, a reciprocidade aconteceu, pois eles com seus questionamentos, suas sugestões e entusiasmo, demonstraram à professora experiente que sou, que tenho ainda algo, ou muito a aprender (CORRADI, 2005, p. 83).

Segundo a referida autora, a relação de parceria entre professora experiente (aquela que já no exercício da função recebe em suas aulas alunos estagiários, tidos como professores iniciantes) e professores iniciantes (estagiários), propicia ricas possibilidades de aprendizagens e de identificação com a docência, uma vez que essa relação pode promover o encontro de discursos da cultura científica e da cultura escolar, trazendo à tona o contexto intercultural que, se considerado na formação docente, em muito pode contribuir para a melhoria não só da formação, como também da atuação docente.

Também o trabalho desenvolvido por Rodrigues (2009) aborda a questão da instituição de um sistema de parcerias na formação docente. Em sua pesquisa, a autora apresenta importantes contribuições para as reflexões acerca da parceria universidade e escola básica na formação docente; bem como do papel do Estágio Curricular Supervisionado nesse processo. A referida autora defende o estabelecimento de um sistema de parceria entre as instituições formadoras (Universidades e Escolas Básicas), nos cursos de formação de professores.

No entanto, apoiada em seus achados, afirma que, embora seja possível detectar propostas interessantes de modificação na estrutura e condução do Estágio Curricular Supervisionado - no intuito de torná-lo mais significativo para os estudantes - elas ainda permanecem presas na visão da universidade como locus de formação docente, não considerando as escolas de Educação Básica como espaço de formação de professores e, sim, apenas como locais de aplicação da prática.

Nesse sentido, a referida autora reforça a importância de esforços no sentido de buscar um sistema de parceria, enfatizando acreditar que:

[...] a falta de enfoque sobre o lugar da escola na formação de professores, ou mesmo seu reconhecimento, se deva à tradição dos cursos de formação docente brasileiros em não priorizar a formação pedagógica e prática, bem como a superposição dos conhecimentos ditos "científicos" àqueles ditos da “experiência”[...] (RODRIGUES, 2009, p. 29). 
Pode-se observar que as pesquisas acima estão de acordo entre si no que se refere ao fato do Estágio Curricular Supervisionado ser concebido e conduzido como elo entre universidade e escolas do ensino básico, na efetivação de relações de parcerias na formação inicial e contínua dos docentes.

Em pesquisa de doutoramento, Borges (2012) constata que a objetivação do Estágio Curricular Supervisionado, conforme previsto na legislação educacional e como defende a respectiva literatura acadêmica, efetiva-se nos modos pelos quais os professores supervisores e os professores parceiros concebem e fazem o Estágio.

Segundo o referido autor, as vozes dos sujeitos entrevistados revelam que o Estágio Curricular Supervisionado se efetiva pelas relações de parceria nele estabelecidas. Muito mais do que simplesmente denunciar a falta de infraestrutura oferecida ao desenvolvimento do Estágio Curricular Supervisionado, é no interior das relações que se estabelecem entre professores supervisores, professores parceiros, alunos estagiários; e entre universidades e escolas básicas, que se efetivam práticas alternativas nas quais se objetivam o Estágio Curricular Supervisionado.

Essas relações, que são a materialização de uma parceria, são eivadas de posturas e de alternativas viáveis e necessárias para a superação dos obstáculos gerados pela falta de infraestrutura. A pesquisa revela que as atividades do Estágio Curricular Supervisionado, conforme previstas na legislação educacional, só se efetivam mediante os esforços de tais sujeitos pelo estabelecimento de um sistema de parceria de fato, que, lamentavelmente, tem se efetivado mais no âmbito interpessoal.

A pesquisa também revela a constante luta pelo estabelecimento de uma parceria, tanto por parte dos professores supervisores, ou seja, professores responsáveis pela disciplina Estágio Curricular Supervisionado, como também por parte dos professores experientes, atuantes na Educação básica. Esses últimos, ao receber e acompanhar alunos estagiários em suas salas de aulas atuam como parceiros.

Dessa forma, justifica-se a implantação de um sistema de parceria, verdadeiramente institucionalizada de direito e de fato. Essa relação contribui para a objetivação de um Estágio Curricular Supervisionado, encarado como campo de conhecimento, a ser trabalhado de maneira significativa, tanto para os futuros professores, quanto para os próprios professores supervisores e parceiros com ele envolvidos.

Vale lembrar que, na pesquisa sobre o estado da arte da formação de professores no Brasil, André et al (1999) denunciam, especificamente no que se refere à formação inicial e continuada, a ausência de um projeto que explicite claramente o tipo de profissional que se 
almeja formar para a Educação Básica. Em função disso, o estudo aponta a relevância e a necessidade de se definir uma política que garanta uma integração mais orgânica entre as agências que formam os professores e as secretarias de Educação. Essa política seria o que chamamos, aqui, de relações de parceria na formação docente.

Pertinente também considerarmos a pesquisa coordenada por Gatti e Nunes (2008), que trata da relação entre currículos de Licenciaturas, ementas de disciplinas, traçando um contraponto com a bibliografia destinada a concursos públicos de professores para atuarem nas respectivas áreas para as quais foram licenciados. Este estudo denuncia características inadequadas da relação entre grade curricular, ementas e bibliografia para se ensinar com esses currículos, evidenciando um verdadeiro gargalo propiciado pelo distanciamento dos cursos de formação inicial com as escolas de educação básica e sistemas de ensino. Tal estudo, ao mostrar essa distância, consequentemente revela a falta de comunicação entre as diferentes instâncias: escola básica e universidade.

\section{Palavras finais: um convite à continuidade das reflexões}

Os achados das pesquisas acima mencionadas revelam vozes prenhes de sinais e de pistas que apontam, implícita ou explicitamente, para a importância, a necessidade e mesmo a urgência do estabelecimento de um sistema de parcerias institucionalizado, de direito e de fato, na formação docente.

A propósito, a institucionalização das relações de parceria na Educação pode ser situada no plano intencional da legislação, como, por exemplo, na Lei de Diretrizes e Bases da Educação Nacional (Lei 9394/96), quando em seu Título IV - Da organização da Educação Nacional, se refere ao chamado "regime de colaboração" entre as esferas do poder público da União, dos estados e municípios, nos processos organizativos e de gestão.

Destacam-se, ainda, as recomendações do Conselho Nacional de Educação, constantes dos Pareceres CNE/CP 9/2001; 21/2001; 27/2001 e 28/2001, ao estipularem a necessidade de estabelecimento de um sistema de convênio entre as instituições formadoras e sistemas de ensino para a realização do Estágio Curricular Supervisionado. Esse convênio já é, em si, uma relação de parceria.

Acredita-se, portanto, que esse conjunto de pareceres forneça jurisprudência para se desencadear debates e reflexões que possam subsidiar o Conselho Nacional de Educação e/ou outros órgãos governamentais responsáveis, no sentido de proporem a regulamentação das relações de parceria. Traçando assim, diretrizes para efetivação de propostas de 
institucionalização, de direito e de fato, dessas relações de parceria na formação e profissionalização docente, envolvendo os cursos formadores das universidades e unidades escolares em suas respectivas secretarias de Educação.

Utopicamente, mas com o objetivo de provocar e instigar novos olhares e novas reflexões, uma alternativa para a efetivação de uma relação institucional de parceria na formação docente seria a de reconhecer os sistemas estaduais e municipais de ensino como co-responsáveis pela formação docente. Nesse caso, propor aos referidos sistemas que promovam uma redistribuição dos encargos didáticos de seus docentes. Essa redistribuição de encargos implicaria na redução do número de aulas semanais, com atribuição de carga horária para professor que recebesse, em suas aulas, licenciandos para realização de Estágio. Por exemplo, para cada grupo de três estagiários, poderia reduzir uma aula semanal... eis um caminho possível e necessário, porém, mais do que uma proposta, fica aqui um convite às reflexões.

\section{REFERÊNCIAS}

ANDRE, M.; SIMOES, R. H. S.; CARVALHO, J. M.; BRZEZINSKI, I. Estado da Arte na formação de professores no Brasil. Educação e Sociedade. Campinas-SP, ano XX, v. 20, n. 68, p. 301-309, dez.1999. Disponível em: http://www.scielo.br/scielo.php?pid=S010173301999000300015\&script=sci_abstract\&tlng=pt. Acesso em: 2 abr. 2019. DOI: https://doi.org/10.1590/S0101-73301999000300015

BARDIN, L. Análise de Conteúdo. Lisboa: Edições 70, 1988.

BOM MEIHY, J. C. S. Manual de História Oral. São Paulo: Loyola, 1996.

BORGES, V. J. Modos de realizar Estágio Curricular Supervisionado em Geografia: vozes de professores supervisores e professores parceiros na Região Sudeste (Brasil). Orientadora: Marilda da Silva. 2012, 251f. Tese (Doutorado em Educação Escolar). Universidade Estadual Paulista. Araraquara-SP, 2012. Disponível em: https://repositorio.unesp.br/handle/11449/101551?locale-attribute=en. Acesso em: 2 abr. 2019.

BRASIL. Lei n. 9.394, de 20 de dezembro de 1996. Estabelece as Diretrizes e Bases da Educação Nacional. Diário Oficial da União, Brasília-DF. 20 de nov. de 1996. Disponível em: http://www.planalto.gov.br/ccivil_03/leis/19394.htm. Acesso em: 2 abr. 2019.

BRASIL. Parecer CNE/CP 009/2001 de 08.05.2001, do Conselho Nacional de Educação. Diretrizes Curriculares Nacionais para a Formação de Professores da Educação Básica, em nível superior, curso de Licenciatura, de Graduação plena. Disponível em http://portal.mec.gov.br/cne/arquivos/pdf/009.pdf. Acesso em: 2 abr. 2019. 
BRASIL. Parecer CNE/CP 21/2001, de 06.08.2001, do Conselho Nacional de Educação. Dispõe sobre a duração e carga horária dos cursos de Formação de Professores da Educação Básica, em nível superior, curso de Licenciatura, de Graduação plena. Disponível em http://portal.mec.gov.br/dmdocuments/cnecp_212001.pdf. Acesso em: 2 abr. 2019.

BRASIL. Parecer CNE/CP 27/2001, de 02.10.2001, do Conselho Nacional de Educação. Dá nova redação ao Parecer CNE/CP 9/2001, que dispõe sobre as Diretrizes Curriculares Nacionais para a Formação de Professores da Educação Básica, em Cursos de Nível Superior. Disponível em http://portal.mec.gov.br/cne/arquivos/pdf/027.pdf. Acesso em: 2 abr. 2019.

BRASIL. Parecer CNE/CP 28/2001 de 02.10.2001, do Conselho Nacional de Educação. Dá nova redação ao Parecer CNE/CP 21/2001, que estabelece a duração e a carga horária dos cursos de Formação de Professores da Educação Básica, em nível superior, curso de Licenciatura, de Graduação plena. Disponível em http://portal.mec.gov.br/cne/arquivos/pdf/028.pdf. Acesso em: 2 abr. 2019.

CORRADI, D. P. Estágio Supervisionado: cultura(s) e processos de identificação permeando um currículo de formação de professores de Química. Orientadora: Maria Ines Petrucci Rosa. 2005. 99 f. Dissertação (Mestrado em Educação). UNICAMP, Campinas-SP, 2005. Disponível: http://repositorio.unicamp.br/jspui/handle/REPOSIP/253115. Acesso em: 2 abr. 2019.

DELGADO, L. A. N. História Oral - Memória, tempo, identidade. Belo Horizonte-MG: Autêntica, 2006.

FOERSTE, E. Parceria na formação de professores. Revista Iberoamericana de Educación, v. 34, n. 3, p. 1-13, 2004. Disponível em: https://rieoei.org/RIE/article/view/3547 Acesso em 13 de mar. 2019. DOI: https://doi.org/10.35362/rie36133547

FOERSTE, E. Parceria na formação de professores. São Paulo: Cortez, 2005.

GATTI, B.; NUNES, (coord.). Relatório final: estudo dos cursos de Licenciatura no Brasil: letras, matemática e ciências biológicas. Rio de Janeiro: Fundação Carlos Chagas, 2008. $137 \mathrm{p}$.

GAUTHIER, C. Por uma teoria da Pedagogia: pesquisas contemporâneas sobre o saber docente. Ijuí-RS: Unijuí, 1998. 480p.

PIMENTA, S. G.; LIMA, M. S. L. Estágio e Docência. 5. ed. São Paulo: Cortez, 2010.

RODRIGUES, P. A. M. Anatomia e fisiologia de um Estágio. Orientadora: Menga Lüdke. 2009, 140 f. Dissertação (Mestrado em Educação). Pontifícia Universidade Católica do Rio de Janeiro. Rio de Janeiro, 2009. Disponível em: https://www.maxwell.vrac.pucrio.br/colecao.php?strSecao=resultado\&nrSeq=14119@1. Acesso em: 2 abr. 2019. DOI: https://doi.org/10.17771/PUCRio.acad.14119

SANTOS, B. de S. Modernidade, identidade e a cultura de fronteira. Tempo Social; Rev. Sociol. USP, S. Paulo, v. 5, n. 1-2, p. 31-52, 1993 (editado em nov. 1994). Disponível em: http://www.scielo.br/scielo.php?pid=S0103- 
20701993000100031\&script=sci_abstract\&tlng=pt. Acesso em: 2 abr. 2019. DOI:

https://doi.org/10.1590/ts.v5i1/2.84940

TARDIF, M. Princípios para guiar a aplicação dos programas de formação inicial para o ensino. Anais do XIV ENDIPE: trajetórias e processos de ensinar e aprender: Didática e formação de professores. XIV ENDIPE, 27 a 30 de abril de 2008. PUC/Porto Alegre, RS. 2008. p.17-46.

TARDIF, M. Saberes profissionais dos professores e conhecimentos universitários. Elementos para uma epistemologia da prática profissional dos professores e suas consequências em relação à formação para o magistério. Revista Brasileira de Educação, n. 13, p.5-24, jan./fev./mar./abr. de 2000. Disponível em: http://educa.fcc.org.br/pdf/rbedu/n13/n13a02.pdf. Acesso em: 2 abr. 2019.

VALLADARES, M. T. R. Vivências em Zonas de fronteiras...as narrativas se fazem travessias... (Um estudo com narrativas e com os cotidianos no estágio curricular da licenciatura em Geografia na UFES). 2009. 276 f. Tese (Doutorado em Educação). Universidade Federal do Espírito Santo. Vitória-ES, 2009. Disponível em: . Acesso em: 2 abr. 2019.

\section{Como referenciar este artigo}

BORGES, Vilmar José. Parceria na form(ação) docente: o estágio curricular supervisionado como lugar de fronteira dos cursos de formação e a educação básica. Revista IberoAmericana de Estudos em Educação, Araraquara, v. 15, n. 2, p. 422-435, abr./jun. 2020. eISSN: 1982-5587. DOI: https://doi.org/10.21723/riaee.v15i2.12482

Submetido em: 04/03/2019

Revisões requeridas: 20/05/2019

Aprovado em: 18/09/2019

Publicado em: 20/02/2020 